Trên đây là kết quả nghiên cứu được thực hiện trên nhóm bệnh nhân đang điều trị nghiện các chất dạng thuốc phiện bằng thuốc thay thế tai 3 tỉnh Điên Biên, Sơn La, Lai Châu. Chúng tôi nhận thấy vẫn còn một số hạn chế nhất định. Bao gồm việc lựa chọn đối tượng nghiên cứu có chủ đích, các thông tin thu được thông qua việc phỏng vấn trực tiếp vì vậy bệnh nhân phải nhớ lại tiền sử sử dụng chất,... Chính vì vậy có thể dẫn đến sai số chọn hoặc sai số do việc nhớ lại thông tin. Mặc dù các phương pháp làm giảm sai số đã được thực hiên tuy nhiên đăc điểm các đối tượng vẫn chưa thể hoàn toàn đại diên được cho các bệnh nhân nghiện chất tại các địa phương nghiên cứu.

\section{KẾT LUÂN}

Bệnh nhân tham gia điều trị nghiên các chất dạng thuốc phiện bằng thuốc thay thế năm 2019 tại 3 tỉnh miền núi phía bắc chủ yếu là nam giới trong độ tuổi lao động. Phần lớn là người dân tộc thiểu số. Khoảng 1 phần 4 số bệnh nhân chưa từng được đến trường hoặc không biết chữ. Chủ yếu các đối tượng sử dụng các chất gây nghiện dạng thuốc phiện như heroin hoặc thuốc phiện. Số đối tượng sử dụng qua nhiều loại chất trong quá khứ đạt tỷ lệ gần $30 \%$. Bệnh nhân sử dụng heroin có tuổi sử dụng lần đầu trung bình là 26.21 tuổi cho cả 2 nhóm điều trị. Đường dùng chủ yếu là hút và tiêm truyền tĩnh mạch. Số bệnh nhân nhiễm HIV ở hai nhóm là 26 , trong đó 9 người ở nhóm methadone, 17 người ở nhóm buprenorphine. Thông qua phỏng vấn trực tiếp các bệnh nhân tham gia điêuu trị, nhóm nghiên cứu đã đưa ra được một số đặc điểm của đối tượng, qua đó giúp cho những cán bộ thực hiện công tác điều trị có thể hiểu được người bệnh, giữ an toàn cho bản thân cũng như góp phần tăng cường hiệu quả điều trị cho bệnh nhân.

\section{TÀI LIÊU THAM KHẢO}

1. Bô Y tế (2019), Báo cáo Tổng kết, đánh giá 10 năm triển khai Chương trình điều trị thay thế nghiện các chất dạng thuốc phiện bằng thuốc Methadone, Hà Nôi

2. Bộ Y tế (2018), Hướng dẫn: Điều trị nghiện các chất dạng thuốc phiện bằng thuốc Buprenorphine, Hà Nội.

3. Nguyễn Thị Minh Tâm Một số đặc điểm xã hội và sư dung ma túy của bệnh nhân mới điều trị methadone tại Điện Biên, Lai Châu và Yên Bái năm 2014, Tap chí Y học dự phòng.

4. Trung H.Q., Bộ Đ.T., Ngọc N.X. và cộng sự. (2015). Kết quả chướng trình điều trị nghiện các chất dang thuốc phiên bằng thuốc methadone tại tỉnh Phú Thọ năm 2015. 12.

5. Hser Y.-I., Saxon A.J., Huang D. và công sư. (2014). Treatment retention among patients randomized to buprenorphine/naloxone compared to methadone in a multi-site trial. Addiction, 109(1), 79-87.

6. Vuong T., Shanahan M., Nguyen N. và cộng sứ. (2016). Cost-effectiveness of center-based compulsory rehabilitation compared to communitybased voluntary methadone maintenance treatment in Hai Phong City, Vietnam. Drug Alcohol Depend, 168, 147-155.

7. Bộ Y tế (2020), Báo cáo: Kết quả công tác phòng, chông HIV/AIDS năm 2019 và nhiệm vụ trọng tâm năm 2020, .

\title{
ÁP DỤNG KỸ THUÂTT GIẢI TRÌNH TỰ GEN PHÁT HIÊ̂N ĐỘT BIẾN ĐIỂM GEN CYP21A2 GÂY BÊ̂NH TĂNG SẢN THƯợNG THẬN BẨM SINH THỂ THIẾU 21-HYDROXYLASE
}

\section{TÓM TẮT}

Tăng sản thượng thận bẩm sinh (TSTTBS) do thiếu hưt enzym 21-hydroxylase là bệnh di truyền lặn nhiễm sắc thể thường gây nên do đột biến gen CYP21A2.

*Trường Đai học Y Hà Nội,

**Bênh viển Nhi Trung ướng

Chịu trách nhiệm chính: Vũ Chí Dũng

Email: dungvu@nch.org.vn

Ngày nhân bài: 11.01.2021

Ngày phản biên khoa hoc: 17.3.2021

Ngày duyệt bài: 29.3.2021
Trần Vân Khánh*, Trần Huy Thịnh*, Ngô Thị Thu Hương*, Vũ Chí Dũng****

Các dạng đột biến gen CYP21A2 bao gôm đột biến điểm và đột biến xóa đoạn, trong đó đột biến điểm chiếm tỉ lệ cao hơn, chiếm khoảng $60 \%$. Nghiên cứu này được thực hiện với mục tiêu: xác định đột biến điểm trền bệnh nhân tăng sản thượng thận bẩm sinh thể thiếu hụt enzym 21- hydroxylase băng kỹ thuât giải trình tự gen. 50 bệnh nhân được chẩn đoán xác định bệnh tăng sản thượng thận bẩm sinh thể thiếu enzym 21- hydroxylase; kỹ thuât giải trình tự gen được áp dụng để xác định đột biển. Kết quả phát hiện $32 / 50(64 \%)$ bệnh nhân có đột biến điểm gen CYP21A2. Trong số các bệnh nhân phát hiện được đột biến, $53 \%$ đột biến được phát hiện trên bệnh nhân 
thể bệnh mất muối, 38\% trên các bệnh nhân thể nam hóa đợn thuần và $9 \%$ trên các bệnh nhân thể không cổ điển. Đột biến đồng hợp tử chiếm $62,5 \%$, đột biến di hợp tử chiếm $37,5 \%$. Nghiên cứu phát hiến đưước 7 kiểu gen trong đó kiểu gen có tỉ lệ cao nhất lì $\mathrm{I} 2 \mathrm{~g} / \mathrm{I} 2 \mathrm{~g}$ $(31,3 \%)$, đứng thứ hai là $\mathrm{I} 2 \mathrm{~g} / \mathrm{p} . \mathrm{I} 172 \mathrm{~N}(18,7 \%)$, các kiểu gen còn lại chiếm tỉ lệ từ 3,1-15,6\%.

Tư khóa: TSTTBS, đột biến điểm gen CYP21A2, giải trình tự gen

\section{SUMMARY \\ IDENTIFICATION OF POINT MUTATION IN THE CYP21A2 GENE IN CONGENITAL ADRENAL HYPERPLASIA USING SEQUENCING METHOD}

Congenital adrenal hyperplasia (CAH) due to deficiency of the enzyme 21-hydroxylase is an autosomal recessive disorder commonly caused by mutations in the CYP21A2 gene. Point mutation is the most common mutation in $\mathrm{CAH}$ (about $60 \%$ ) and identifying point mutation requires the use of gene sequencing. The study was conducted with the aim of identifying point mutations in patients with congenital adrenal hyperplasia due to 21-hydroxylase deficiency using sequencing method. METHODS: 50 patients were diagnosed with 21-hydroxylase-deficient hypercholesterolemia was analyzed by gene sequencing. Results: $32 / 50$ point mutation (64\%) of patients, including $62.5 \%$ homozygous mutation and $37.5 \%$ heterozygous. Salt wasting accounted for $53 \%$ of patients, simple virilizing accounted for $38 \%$ and non-classical accounted for $9 \%$. The most common genotypes were I2g/I2g (31.3\%), I2g/p.I172N (18.7\%), remaining genotypes are ranging from $3.1-15.6 \%$.

Keywords: Congenital Adrenal Hyperplasia, CYP21A2 point mutation, gene sequencing

\section{I. ĐẶT VẤN ĐỀ}

Tăng sản thượng thận bẩm sinh (TSTTBS) thể thiếu 21-hydroxylase xảy ra do khiếm khuyết một phần hoặc hoàn toàn của enzym 21hydroxylase tham gia tổng hợp cortisol từ cholesterol ở tuyến thượng thận. Mức độ nặng của các triêu chứng lâm sàng khác nhau và phụ thuộc vào hoạt độ 21-OH [1], [2]. Mặc dù gianh giới khác nhau về biểu hiện kiểu hình đôi khi khó phân biệt nhưng kiểu hình lâm sàng được chia ra thành thể cổ điển hay thể nặng và thể không cổ điển hay thể nhẹ của bệnh. Thể cổ điển được chia thành thể cổ điển mất muối (MM) (salt wasting - SW) và nam hóa đơn thuần (NHĐT) (simple virilizing - SV) phản ánh mức độ thiếu hụt aldosterone [3], [4]. Thể cổ điển mất muối chiếm $75 \%$ các ca mắc thể cổ điển. Thiếu hut hoàn toàn hoạt độ enzym gây nguy hiểm đển tính mạng và tử vong do mất nước, hạ natri máu (thể mất muối).

Enzym 21-Hydroxylase được mã hóa bởi gen CYP21A2, hoạt độ enzym của bệnh nhân phụ thuộc vào kiểu đột biến khác nhau. Giải trình tự gen là kỹ thuật thường quy để xác định đột biến điểm trên gen CYP1A2 ở bệnh nhân TSTTBS. Việc xác định đột biến có ý nghĩa quan trọng trong chẩn đoán xác định bệnh bệnh, đặc biệt với những trường hợp không điển hình. Kết quả đột biến gen sẽ giúp phát hiện người lành mang gen bệnh, chẩn đoán trước sinh cho các thành viên gia đình để tư vấn di truyền giúp ngăn ngừa và làm giảm tỷ lệ mắc bệnh. Do vậy, đề tài được thực hiện với mục tiêu: Xác định đột biến điểm gen CYP21A2 trên bệnh TSTTBS thể thiếu hụt enzym 21-hydroxylase băng kỹ thuật giải trinh tư gen.

\section{II. ĐỐI TƯỢNG VÀ PHƯƠNG PHÁP NGHIÊN CứU}

1. Đối tượng. 50 bệnh nhân TSTTBS thể thiếu enzym 21-hydroxylase được chẩn đoán và điều trị tại Khoa Nội tiết - Chuyển hóa - Di truyền, Bệnh viện Nhi Trung ương. Nghiên cứu được tiến hành tại Bệnh viện Nhi Trung ương và Trung tâm nghiên cứu Gen-Protein, Trường Đại học $Y$ Hà Nội trong khoảng thời gian từ 1/2017$6 / 2020$.

\section{Phương pháp}

2.1. Kỹ thuật tách chiết DNA. DNA được tách chiết từ bạch cầu máu ngoại vi theo quy trình phenol/chloroform. Tất cả các mẫu DNA sẽ được tiến hành đo nồng độ và độ tinh sạch, chỉ có mẫu DNA đạt giá trị $\geq 1,8$ mới đạt yêu cầu về tinh sạch và được sử dụng để phân tích.

2.2 Kỹ thuật giải trình tự gen. Toàn bộ chiều dài gen CYP21A2 được khuếch đại bằng phản ứng PCR với các cặp mồi đặc hiệu.

- Thành phần phản ứng: thế tích $20 \mu \mathrm{l}$ gồm: 100 - 150 ng DNA, 5 pmol primer, $200 \mu \mathrm{mol} / \mathrm{l}$ dNTP, 2 đơn vị enzym Taq polymerase và $2 \mu \mathrm{l}$ GeneAmp $10 x$ buffer.

- Chu trình nhiệt: $94^{\circ} \mathrm{C} / 5$ phút, $\left[94^{\circ} \mathrm{C} / 1\right.$ phút, $60^{\circ} \mathrm{C} / 1$ phút, $72^{\circ} \mathrm{C} / 1$ phút $] \quad x \quad 35$ chu kỳ, $72^{\circ} \mathrm{C} / 2$ phút, giữ ở $15^{\circ} \mathrm{C}$. Sản phẩm $\mathrm{PCR}$ được điện di trên gel agarose $1 \%$, 90V trong 30 phút.

- Sản phẩm PCR sau khi điện di trên gel agarose được tinh sạch bằng Gel purification Kit trước khi tiển hành giải trình tự gen. Để giải trình tự được toàn bộ gen CYP21A2, sử dụng các mồi như đã mô tả ở bảng 2.1. Quy trình được thực hiện theo phương pháp BigDye terminator sequencing (Applied Biosystems, Foster city, USA).

Kết quả giải trình tự gen được phân tích bằng phần mêm CLC Main Workbench. Mẫu DNA của bệnh nhân được so sánh với mẫu DNA đối chứng và trình tự của CYP21A2 trên GeneBank (Accession number NM_0005002).

3. Đạo đức nghiên cứu trong $Y$ học. Nghiên cứu tuân thủ tuyệt đối các quy định về 
đạo đức trong nghiên cứu y sinh. Bệnh nhân hoàn toàn tự nguyện tham gia vào nghiên cứu. Bệnh nhân hoàn toàn có quyền rút lui khỏi nghiên cứu khi không đồng ý tiếp tục tham gia vào nghiên cứu. Bệnh nhân sẽ được thông báo về kết quả xét nghiệm gen để giúp cho các bác sỹ tư vấn di truyên hoặc lựa chọn phác đồ điều trị phù hợp. Các thông tin cá nhân sẽ được đảm bảo bí mật.

\section{KẾT QUẢ NGHIÊN CỨU}

Trong nghiên cứu này, đã phát hiện 32/50 (64\%) bệnh nhân có đột biến điểm gen
CYP21A2. Đôt biến đồng hợp tử chiếm $62,5 \%$ và dị hợp tử chiếm 37,5\%. Nghiên cứu phát hiện được 7 kiểu gen trong đó kiểu gen có tỉ lệ cao nhất là $\mathrm{I} 2 \mathrm{~g} / \mathrm{I} 2 \mathrm{~g} \quad(31,3 \%)$, đứng thứ hai là $\mathrm{I} 2 \mathrm{~g} / \mathrm{p} . \mathrm{I} 172 \mathrm{~N}(18,7 \%)$, các kiểu gen còn lại chiếm tỉ lệ từ 3,1-15,6\% (Bảng 1).

Các kiểu gen gây thể bệnh mất muối là I2g/I2g，I2g/p.R356W， p.R356W/p.R356W. Kiểu gen gây thể nam hóa đơn thuần là I2g/p.I172N, p.I172N/p.I172N và p.R356W/p.401L. Kiểu gen p.V281L/p.L307FfsX6 gây thể bệnh không điển hình.

\section{Bảng 1. Kêt quả phát hiện đột biến điểm gen CYP21A2 của bệnh nhân}

\begin{tabular}{|c|c|c|c|c|c|}
\hline Số $\mathbf{T}$ & Kiếu gen & Thế bệnh & Dạng đột biến & Số ca bệnh(n) & Tỷ lệ \% \\
\hline 1 & I2g/I2g & Mất muối & Homozygous & 10 & 31,3 \\
\hline 2 & I2g/p.I172N & Nam hóa đơn thuần & Heterozygous & 6 & 18,7 \\
\hline 3 & I2g/p.R356W & Mất muô̂i & Heterozygous & 2 & 6,3 \\
\hline 4 & p.I172N/p.I172N & Nam hóa đơn thuần & Homozygous & 5 & 15,6 \\
\hline 5 & p.V281L/ p.L307FfsX6 & Không cố điến & Heterozygous & 3 & 9,4 \\
\hline 6 & p.R356W/p.R356W & Mất muối & Homozygous & 5 & 15,6 \\
\hline 7 & p.R356W/p.P401L & Nam hóa đơn thuần & Heterozygous & 1 & 3,1 \\
\hline & Tống cộng & & & $\mathbf{3 2}$ & $\mathbf{1 0 0 \%}$ \\
\hline
\end{tabular}

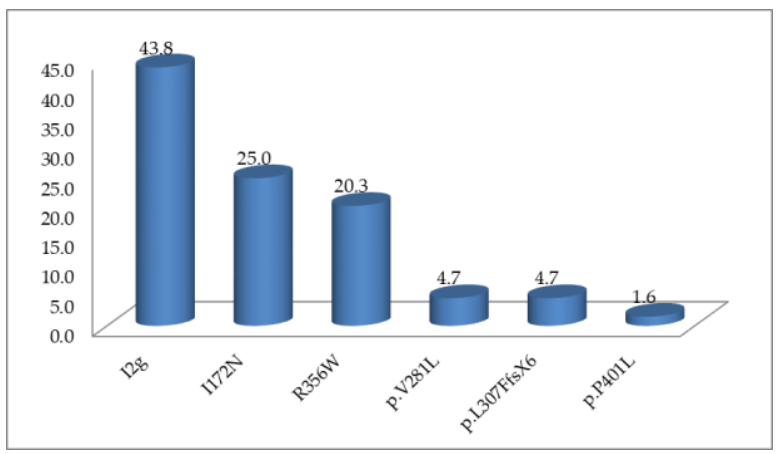

Hình 1: Tỉ lệ các allele đột biến

Hình 1 mô tả tỉ lệ các allele đột biến trong đó allele có tỉ lệ cao nhất là $\mathrm{I} 2 \mathrm{~g}(43,8 \%)$, tiếp đến là I172N $(25 \%)$, các allele đột biến khác có tỉ lệ thấp hơn là R356W $(20,3 \%)$, p.V281L $(4,7 \%)$, p.L307FfsX6 $(4,7 \%)$ và p.P401L $(1,6 \%)$.

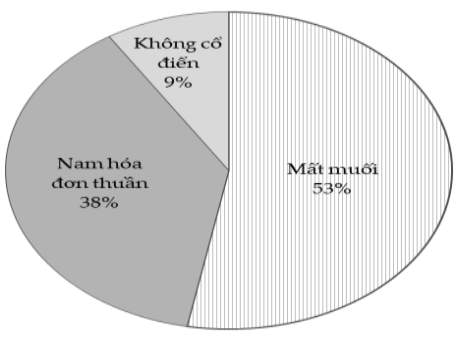

Hình 2: Tỉ lệ các thể bệnh

Trong số các bênh nhân phát hiện được đột biến, 53\% đột biển được phát hiện trên bệnh nhân thể bênh mất muối, 38\% trên các bệnh nhân thể nam hóa đơn thuần chiếm và $9 \%$ trên các bệnh nhân thể không cổ điển (Hình 2).
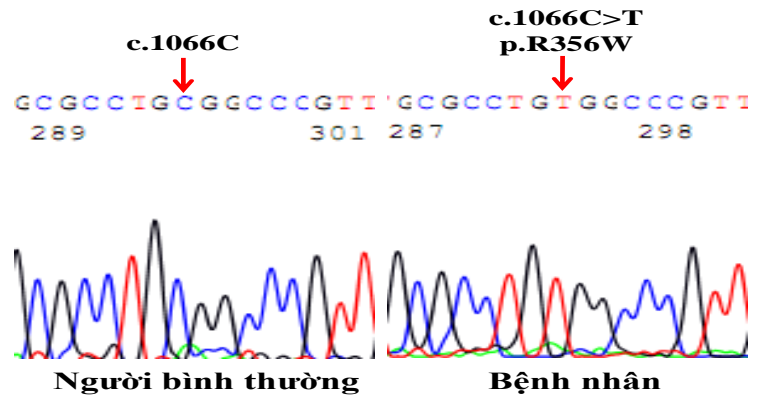

Hình 3: Kêt quả giải trinh tư gen CYP21A2 - Hình ảnh đột biến đồng hớp tứ p.R356W

Kết quả giải trình tự của bệnh nhân trong hình 3 cho thây bệnh nhân có đột biến thay thế nucleotide $T$ thành $C$ ở vị trị 1066 trên trình tự c.DNA. Đột biến này làm thay đổi bộ ba mã hóa ở vị trí 356 từ CGG (Arginine- R) thành TGG (Tryptophan- W).

\section{BÀN LUÂ̂N}

Trong nghiên cứu này, 50 bệnh nhân TSTTBS thiếu 21-OH đã được giải trình tự gen CYP21A2 để tìm đột biến, kểt quả cho thấy 32/50 (64\%) bệnh nhẩn đã được tìm thây đột biến. Kiểu gen thường gặp nhất là $\mathrm{I} 2 \mathrm{~g} / \mathrm{I} 2 \mathrm{~g}(31,25 \%)$, đứng thứ hai là I2g/p.I172N (18,75\%), tiếp đó là các kiểu gen p.I172N/p.I172N và p.R356W/p.R356W. Các 
kiểu gen chủ yếu gây thể bệnh mất muối là I2g/I2g, I2g/p.R356W, p.R356W/p.R356W. Kiểu gen gây nên thể nam hóa đơn thuần là I2g/p.I172N, p.I172N/p.I172N và p.R356W/ p.401L. Kiểu gen p.V281L/ p.L307FfsX6 dẫn đến thể bệnh không điển hình. Kết quả này phù hợp với các nghiên cứu in silico và in vitro nghiên cứu mức độ ảnh hưởng của đột biến lên chức năng của 21-hydroxylase, trong đó các đột biến nặng như $\mathrm{I} 2 \mathrm{~g}$ và $\mathrm{R} 356 \mathrm{~W}$ thường gây mất hoàn toàn chức năng của $21-\mathrm{OH}$ do vậy gây nên thể mất muối, các kiểu gen di hợp tử với p.I172N, p.401L, V281L sẽ bảo tồn được 1 phần hoạt độ của $21-\mathrm{OH}$ do đó gây ra thể bệnh nhe hơn như nam hóa đơn thuần hoặc thể không cổ điển [3].

Nghiên cứu phát hiện 6 allele đột biến: I2g, p.I172N， p.R356W， p.V281L， p.L307fsX6 và p.P401L. Allele đột biến có tỉ lệ cao nhất là $\mathrm{I} 2 \mathrm{~g}$ $(43,8 \%)$, tiếp đến là $\mathrm{I} 172 \mathrm{~N}(25 \%)$, các allele đột biến khác có tỉ lệ thấp hơn là R356W (20,3\%), p.V281L $(4,7 \%), p . L 307 F f s X 6(4,7 \%)$ và p.P401L $(1,6 \%)$. Kết quả này tương đồng với nghiên cứu trên bệnh nhân TSTTBS người Trung Quốc với tỉ lệ cao allele đột biến cao nhất là I2g (40\%); đứng thứ hai là allele p.I173N $(22,3 \%)$, tiếp đến là allele R356W (15,4\%). Nghiên cứu của Krone và cộng sự trên người Đức cho thấy allele đột biến có tỉ lệ cao nhất là I2g (30\%), tiếp đến là pI $172 \mathrm{~N}$ $(19,7 \%)$ tuy nhiên allele R356W chỉ chiếm 4,5\%, thấp hơn so với quần thể Việt Nam và Trung Quốc. Sự khác biệt này có thể lý giải bởi sự khác biệt về di truyền giữa quần thể người châu Á và người châu Âu, cũng có thể do sự khác biệt trong tiêu chuẩn lựa chọn nhóm nghiên cứu.

Trong nghiên cứu này, kiểu hình của các bênh nhân TSTTBS thiếu 21-OH được phân tích và phân nhóm: 17 bênh nhân có kiểu hình mất muối, 12 bệnh nhân kiểu hình nam hóa đơn thuần và 3 bệnh nhân kiểu hình thể không cổ điển. Các bệnh nhân kiểu hình không cổ điển chiếm tỷ lệ thấp. kết quả này cũng phù hợp với các nghiên cứu ở nhiều chủng tộc châu Ả như Trung quốc, Hàn quốc [5]; Krone và cộng sự (2000) nghiên cứu phân tích phân tử cho 155 gia đình thì thể cổ điển mất muối chiếm 59,4\% (92/155); thể nam hóa đơn thuần chiếm 33,5\% (52/155) và không cổ điển 7,1\% (11/155) [3]. Các nghiên cứu ở các chủng tộc khác thì thể không cổ điển chiếm tỷ lệ cao hơn nhiều như: $63,2 \%$ các bệnh nhân Tây Ban Nha; $54,7 \%$ các bệnh nhân Hy Lạp và $24,6 \%$ các bệnh nhân Ý [6]. Sự khác nhau này có thể do cỡ mẫu và tiêu chuẩn lựa chọn mẫu trong nghiên cứu khác nhau và có thể có liên quan tới yếu tố chủng tộc.
Trong nghiên cứu của chúng tôi có 3 bệnh nhân mắc thể không cổ điển, cả 3 bệnh nhân đều là trẻ trai và đều có kiểu gen là p.V281L/p.L307FfsX6. Cả 3 trẻ này đều được chẩn đoán nhờ sàng lọc các trẻ trai có xạm da vùng bìu. Theo dõi diễn biến lâm sàng sau 2 đến 12 năm nhận thấy diễn biến phù hợp với thể không cổ điển thiếu 21-OH. Nghiên cứu của Gidlof S và cộng sự (2013) [7], [8] trên các bệnh nhân TSTTBS người Thụy Điển cũng xác định được 38 trẻ bú mẹ mắc thể không cổ điển thiếu 21-OH, các bệnh nhân này đều mang allele đột biến V281L hoặc P31L.

\section{KẾT LUÂ̂N}

Bằng việc áp dụng kỹ thuật giải trình tự, nghiên cứu đã phát hiện được 32/50 (64\%) bệnh nhân có đột biến điểm gen CYP21A2. Trong số các bệnh nhân phát hiện được đột biến, $53 \%$ đột biến được phát hiện trên bệnh nhân thể bệnh mất muối, $38 \%$ trên các bệnh nhân thể nam hóa đơn thuần chiếm và $9 \%$ trên các bênh nhân thể không cổ điển. Đột biến đồng hợp tử chiếm $62,5 \%$ và dị hợp tử chiếm $37,5 \%$. Nghiên cứu phát hiện được 7 kiểu gen trong đó kiểu gen có tỉ lệ cao nhất là $\mathrm{I} 2 \mathrm{~g} / \mathrm{I} 2 \mathrm{~g}(31,3 \%)$, đứng thứ hai là $\mathrm{I} 2 \mathrm{~g} / \mathrm{p} . \mathrm{I} 172 \mathrm{~N}(18,7 \%)$, các kiểu gen còn lại chiếm tỉ lệ từ 3,1-15,6\%.

Lời cám ơn. Nghiên cứu được thực hiện sự giúp đỡ của các cán bộ của Trung tầm nghiên cứu Gen- Protein, Bộ mổn Nhi, Trường Đại học $Y$ Hà Nội; Khoa Nội tiết-Chuyển hóa- Di truyền, Bệnh viện Nhi Trung ương.

\section{TÀI LIÊU THAM KHẢO}

1. White P.C. (2000). Congenital Adrenal Hyperplasia due to 21-Hydroxylase Deficiency. Endocr Rev, 21(3), 245-291.

2. Gonçalves J., Friães A., và Moura L. (2007). Congenital adrenal hyperplasia: focus on the molecular basis of 21-hydroxylase deficiency. Expert Rev Mol Med, 9(11), 1-23.

3. Krone N., Braun A., Roscher A.A. và cộng sự. (2000). Predicting phenotype in steroid 21hydroxylase deficiency? Comprehensive genotyping in 155 unrelated, well defined patients from southern Germany. J Clin Endocrinol Metab, 85(3), 1059-1065.

4. New M.I. (2003). Inborn errors of adrenal steroidogenesis. Mol Cell Endocrinol, 211(1-2), 75-84.

5. Lee H.H., Chao H.T., Lee Y.J. và cộng sự. (1998). Identification of four novel mutations in the CYP21 gene in congenital adrenal hyperplasia in the Chinese. Hum Genet, 103(3), 304-310.

6. Dolzan V., Sólyom J., Fekete G. và cộng sự. (2005). Mutational spectrum of steroid 21hydroxylase and the genotype-phenotype association in Middle European patients with congenital adrenal hyperplasia. Eur J Endocrinol, 153(1), 99-106. 
7. Wedell A., Thilén A., Ritzén E.M. và cộng sự. (1994). Mutational spectrum of the steroid 21hydroxylase gene in Sweden: implications for genetic diagnosis and association with disease manifestation. J Clin Endocrinol Metab, 78(5),
1145-1152.

8. Narasimhan M.L. and Khattab A. (2019) Genetics of congenital adrenal hyperplasia and genotype-phenotype correlation. Fertil Steril, 111(1), 24-29

\title{
MỐI LIÊN QUAN GIŨ̃A CÁC YẾU TỐ THÚC ĐẨY VÀ MỨC Đô BÊ̂NH NÃO GAN LÂM SÀNG THEO TIÊU CHUẨN WEST HAVEN
}

\author{
Võ Duy Thông',2, Hồ Thị Vân Anh ${ }^{1}$
}

\section{TÓM TẮT}

Muc tiêu: Khảo sát mối liên quan giữa các yếu tố thúc đậ̉y và mức độ bệnh não gan (BNG) lâm sàng theo tiêu chuẩn West Haven. Đối tướng và phương pháp: Nghiên cứu cắt ngang mô tả tiến cứu được tiến hành trên 146 bênh nhân xơ gan có biến chứng BNG lâm sàng (BNG độ II, độ III và độ IV theo tiêu chuẩn West Haven). Tiêu chuẩn chẩn đoán xớ gan bao gồm hội chứng suy tế bào gan và hội chứng tăng áp lực tĩnh mach cửa; siêu âm bung hoắc chup cắt lớp vi tính (CT scan) bung cho thấy tổn thương gan mạn (cấu trúc thô, nhiều nốt tân sinh, bờ không đều...). Tiêu chuẩn chẩn đoán BNG lâm sàng bao gồm dựa vào đặc điểm lâm sàng của BNG và loại trừ các nguyên nhẩn khác gây rối loạn tâm thần kinh. Các yếu tố thúc đẩy gồm: Xuất huyết tiêu hoá, nhiễm trùng (Viêm phúc mac nhiễm khuẩn nguyên phát, nhiễm trùng hô hấp, nhiễm trùng tiểu...), hạ kali máu, hạ natri máu, táo bón, tiêu chảy và thuốc an thân. Kết quả: Tuổi trung bình là $51,24 \pm 13,37$, giới tính nam $(71,2 \%)$ nhiêu hơn nữ $(28,8 \%)$. Tỷ lê $\mathrm{BN}$ viêm gan vi rút $\mathrm{B}$ man chiếm phần lớn với $40,4 \%$, tiếp theo là rượu $(21,9 \%)$ và viêm gan vi rút $C$ man $(19,2 \%)$. Yếu tố nhiếm trùng chiếm tỷ lệ cao nhất $(54,1 \%)$, tiếp theo là hạ natri máu, xuất huyết tiêu hoá và hạ kali máu chiếm lần lượt là $37,0 \%, 36,3 \%$ và $33,2 \%$. Yếu tố nhiếm trùng và hạ natri máu có mối liên quan với mức độ bệnh não gan $(p=0,002$ và $p=0,001)$. Kết luận: Yếu tố nhiếm trùng và hạ natri máu có mối liên quạn với bênh não gan và mức độ nặng của bênh lý.

Tì̛ khóa: bệnh não gan, xỡ gan, yếu tố thúc đẩy, nhiếm trùng

\section{SUMMARY}

INVESTIGATION OF THE FACTORS RELATED TO THE SEVERITY OF CLINICAL HEPATIC ENCEPHALOPATHY BESED ON WEST HAVEN CRITERIA

Objective: To investigate the factors associated with the severity of clinical hepatic encephalopathy (BNG) based on West Haven criteria. Methods: A

${ }^{1}$ Đại học Y Dược Thành phố Hồ Chí Minh Bênh viên Chơ Rẫy, Thành phố Hồ Chí Minh

Chịu trách nhiệm chính: Võ Duy Thông

Email: duythong@ump.edu.vn

Ngày nhân bài: 19.01.2021

Ngày phản biên khoa hoc: 16.3.2021

Ngày duyệt bài: 26.3.2021 descriptive cross-sectional study was conducted on 146 cirrhotic patients with clinical complications of BNG (BNG grade II, III and IV according to West Haven criteria). Diagnostic criteria for cirrhosis include hepatocellular insufficiency syndrome and portal hypertension syndrome; abdominal ultrasound or computed tomography (CT scan) of the abdomen with chronic liver damage (rough structure, many neoplastic nodules, irregular margins...). Diagnostic criteria for clinical BNG include clinical characteristics of BNG with excluding other causes of psychosis. The factors including gastrointestinal bleeding, infection (primary infectious peritonitis, respiratory infection, urinary tract infection...), hypokalemia, hyponatremia, constipation, diarrhea and anesthetics were analyzed. Results: The mean age was $51.24 \pm 13.37$, the male gender rate was $71.2 \%$, higher than that of the female $(28.8 \%)$. The proportion of patients with chronic hepatitis due to hepatitis $B$ virus accounted for $40.4 \%$, followed by alcohol $(21.9 \%)$ and hepatitis C virus $(19.2 \%)$. Infectious factor accounted for the highest proportion $(54.1 \%)$, followed by hyponatremia $(37 \%)$, gastrointestinal bleeding $(36.3 \%)$ and hypokalemia (32.3\%). Infectious factors and hyponatremia were associated with the severity of hepatic encephalopathy $(p=0.002$ and $p=0.001)$. Conclusion: Infectious factors and hyponatremia were associated with hepatic encephalopathy and the severity of the disease.

Keywords; hepatic encephalopathy, cirrhosis, predisposing factor, infection

\section{I. ĐĂT VẤN ĐỀ}

Bệnh não gan (BNG) ảnh hưởng đến chất lượng cuộc sống của bệnh nhân (BN), gây rối loạn hành vi và cảm xúc, rối loạn giấc ngủ, giảm sự tương tác với gia đình và xã hội, giảm khả nẳng thực hiện các công việc hằng ngày dễ dẫn đên tai nạn [1]. Bên cạnh đó, sự suy giảm nhận thức ở BN BNG dẫn đễn việc sử dụng những nguồn lực chăm sóc $y$ tế nhiêu hơn so với những biến chứng khác của bệnh gan [2]. Tại Hoa Kí, BNG là nguyên nhân nhập viện thường gặp thứ 2 ở $\mathrm{BN}$ xơ gan $(\mathrm{XG})$ và tỷy lệ hiện mắc của $\mathrm{BNG}$ lâm sàng ở thời điểm chẩn đoán XG là $10-14 \%$ [3]. Trong 5 năm sau chẩn đoán $X G$, nguy cơ xảy ra đợt BNG lâm sàng đầu tiên là $5 \%-25 \%$ và 